\title{
LEALTAD Y PROFESIÓN EN LAS MEMORIAS DE CARLOS PRATS*
}

\author{
Hernán Neira \\ Universidad de Santiago de Chile \\ Santiago de Chile \\ hernan.neira@usach.cl \\ Juan Manuel Fierro \\ Universidad de La Frontera \\ juanmanuel.fierro@ufrontera.cl
}

\begin{abstract}
RESUMEN / ABSTRACT
La interpretación de las Memorias del general Carlos Prats se enfrenta a la dificultad de una escasez de trabajos académicos sobre ellas. Esa dificultad puede ser superada con la orientación de la teoría sobre el género narrativo memorias. Con lo anterior y la ayuda de otras obras literarias del general Prats -fue autor de un cuento premiado-será posible dar con dos conceptos clave para comprenderlas: "historia mítica" y "recuento epistemológico", y concluir que las Memorias narran el desarrollo de un singular concepto de lealtad, que entrará en conflicto con otras formas de lealtad y deslealtad política y militar.
\end{abstract}

Palabras clave: Carlos Prats, género memorias, doctrina Schneider-Prats, historia mítica militar, lealtad militar.

\section{LOYALTY AND PROFESSION IN THE MEMOIRES OF CARLOS PRATS}

The interpretation of Memories by Carlos Prats grows difficult if we consider the scarcity of academic analysis on them. This complexity may be overcome by the orientation of the theory of narrative genres. Considering this theory as well as the support of some literary works by General Prats he was the author of a laureate short story it is possible to reach two key concepts in order to understand his work: "mythic history" and "epistemological recount". We conclude that the Memories relate the formation and application of a unique concept of loyalty, which collides with other forms of loyalty and disloyalty, both political and military.

KEYWORDS: Carlos Prats, memories literary genre, Schneider-Prats doctrine, mythic military history, military loyalty.

Recepción: 24/04/2018 Aprobación: 08/08/2018

* El presente trabajo es fruto de los proyectos \# 1181322 y \#1161253 del Fondo Nacional de Investigación, Ciencia y Tecnología (FONDECYT) 
El año 2004, período en que se le brindaron a Carlos $\operatorname{Prats}^{1}$ los honores reglamentarios correspondientes al sepelio de un ex Comandante en Jefe del Ejército de Chile, se produjo la cúspide de los comentarios públicos post mortem sobre el general asesinado, así como de citas a las Memorias. Testimonio de un soldado (Prats 1985)². A ello se sumó la edición, reedición o puesta en línea de algunos textos que mencionaban elogiosamente su trayectoria y doctrina militar ${ }^{3}$ o bien que contextualizaban el crimen ${ }^{4}$, cuyo carácter fue político, como no menos políticas fueron las referencias hechas a él durante el entierro oficial ${ }^{5}$. Sin embargo, los discursos y artículos de prensa que se refieren a las Memorias no abordan ni la construcción, ni la estructura, ni la forma que adopta el género memoria en la principal obra escrita de Prats. Carlos Prats fue un hombre al que la historia, más que su propósito, lo situó en el epicentro político de Chile, durante el breve período que va del 27 de octubre 1970 al 23 de agosto 1973. Como además, previamente, dedicó

1 Carlos Prats (1915-1974) ingresó a la Escuela Militar en 1931. Asumió como Comandante en Jefe del Ejército de Chile el 28 de octubre de 1970, tras el asesinato del general René Schneider por un grupo de ultraderecha. No fue marxista, ni tampoco allendista, pero Allende lo designa Ministro del Interior y después Ministro de Defensa con motivo de la reconocida fidelidad que Prats tiene a la Constitución. El 2 de noviembre 1972 renuncia al Ministerio de Interior y el 22 de agosto 1973 renuncia también a la comandancia en Jefe del Ejército. El 15 de septiembre de 1973 se exilia en Argentina.

En adelante, Memorias.

Entre otros: Patricio Palma, El ejemplo del general Prats, inicialmente en la revista Araucaria de Chile (Palma) que apareció en línea con el mismo título en el sitio http://www.blest.eu/; o Prats, un proyecto inconcluso, que recoge testimonios y discursos fúnebres, editado por Hernán Soto y Juan Arriagada en 2014 (Soto and Arriagada); reedición electrónica de El general Prats y el gobierno de la Unidad Popular (Amorós 1999). En el homenaje que se le rindió en el Senado de la República de Chile el 30 de septiembre 2014 intervinieron los senadores: Isabel Allende, Alberto Espina, Manuel Antonio Matta, Alejandro Guiller, Hernán Larraín y Juan Pablo Letelier, vinculados a partidos políticos opuestos (González).

$4 \quad$ El crimen del general Prats fue ejecutado el 30 de septiembre 1974 y se fraguó en el Gobierno y el Ejército de Chile: el general Pinochet era militar activo cuando lo ordenó, además de jefe de Estado. Así lo sostiene el juez Alejandro Solís (Solís 2:22 a 2:51). Damos por válidas las decisiones de la Corte Suprema chilena al condenar por el crimen a numerosos oficiales del Ejército de Chile y también por válido que los tribunales de la República Argentina, donde se realizó el crimen, considerasen al general Pinochet como responsable. Sentencia de la Corte Suprema del ocho de julio de dos mil diez. https:/www.cooperativa.cl/noticias/site/ artic/20100708/asocfile/20100708133222/fallo_caso_prats.pdf.

$5 \quad$ Muchas de ellas recogidas en Prats, un proyecto inconcluso (Soto y Arriagada). 
su vida a ejercer de oficial en el Ejército, es comprensible que el interés periodístico o académico no se haya centrado en los aspectos literarios de su trabajo. Se puede afirmar, entonces, que las Memorias de Carlos Prats se encuentran en una situación en algunos aspectos similares a las Mémoires de Charles de Gaulle (de Gaulle 2000 [1954]). No por la pretensión literaria del general francés, pero sí porque comparten el hecho de que ya existe sobre ellas, en el momento de analizarlas, lo que algunos han denominado "un discurso invasor y problemático" (Jouhaud, Ribard y Schapira 2010). Para despejarlo, es necesario entrar "en la fábrica de la obra, y del escritor, que fue acción política” (Jouhaud, Ribard y Schapira 2010).

Falta entonces entrar en la "fábrica" de las Memorias, de un escrito que vincula la actividad política, la vida profesional-militar y la vida personal de Carlos Prats. Esta obra es también literaria, porque incursiona en el género narrativo específico de las memorias, abriendo así la posibilidad de estudiar la relación y confluencia entre el escritor y el hombre de acción a través de una obra suya de carácter narrativo. Por ello, hay una tarea pendiente, que requiere muchos niveles de estudio, uno de los cuales es el eje a la vez temático y temporal que da estructura a la las Memorias de Prats. En consecuencia, consideramos oportuno leer a Prats con la orientación provista por algunos aspectos de la teoría sobre el género memorias. Nuestro trabajo no apunta a los aspectos políticos de las Memorias, sino más bien a los centros de articulación de una narración que puede ser considerada también como "literaria". Eso permite realizar una aproximación al principal escrito de Prats -hay otros- desde un punto de vista distinto que el de la celebración del general constitucionalista o del que provee un documento histórico-político. No desconocemos, de ningún modo, el carácter documental del texto, porque ese componente le es esencial, pero apuntamos más bien a la estructuración del discurso allí contenido. El análisis de la estructura y vínculos de las Memorias con algunos textos literarios de Prats tiene una doble consecuencia: la primera, el desarrollo mismo de un estudio académico sobre el texto y, el segundo, el esclarecimiento del contenido político del mismo, pues su significado político solo se descrifra cabalmente por medio del análisis de sus componentes literarios. 


\section{LAS MEMORIAS DEL GENERAL PRATS. CLAVES DE INTERPRETACIÓN}

En muchas de las memorias posrenacentistas francesas, los autores "estaban en desgracia o retirados de las armas" (Jouhaud, Ribard y Schapira 2010). También Prats escribe desde la desgracia y el retiro de armas y es desde esta postura que el autor da y pide cuentas. Con ello asumimos también que existe cierta identificación entre la persona del narrador de las Memorias y la persona civil de Carlos Prats. Para así asumirlo nos basamos tanto en las declaraciones de las hijas del general Carlos Prats en el sentido de que las Memorias permiten acceder a su pensamiento, a sus motivaciones, a muchas anécdotas personales (Prats Cuthbert y Prats Cuthbert 1984, 14) y porque él mismo entiende que se trata de un testimonio (Memorias 14). Eso no significa, naturalmente, que no haya una construcción literaria del sujeto de la narración, pero sí que no hay motivos fundados para suponer que el narrador haya pretendido distanciarse de la voz de la persona civil que lleva el mismo nombre.

Como en el caso de las Mémoires de De Gaulle, estamos ante el ejercicio literario de un hombre cuya acción y vocación principal más fuerte no es la literaria, sino la militar y la político-militar. Por ello mismo, el ejercicio literario de Prats no es separable de otras formas de acción, a las que en realidad se subordina. Pero las Memorias no son la única actividad literaria que ejerció. Carlos Prats fue también escritor, como lo prueban otras obras de él, la primera de las cuales es la semblanza histórica titulada "Benjamín Vicuña Mackena y las glorias de Chile” (Prats 1957), único artículo no dedicado a la técnica militar, aunque sí a la defensa nacional, publicado en la revista Memorial del Ejército en $1957^{7}$. Y, la segunda, el cuento "Tribunal de honor" (Prats 1986 [1968]), que obtuvo el tercer lugar en el Octavo Concurso de Cuentos del diario El Sur, de Concepción, en 1969. En otras palabras, Carlos Prats se expresó no solo por el mando militar y político que ejerció, sino en obras que pueden ser catalogadas como literarias y que él mismo consideró así, al menos por haber enviado una de ellas a un concurso específicamente literario, que a su vez la reconoció como tal. No cabe duda, entonces, de que una parte de su acción es literaria y que puede ser considerado también un escritor.

$7 \quad$ La revista agrega una nota que dice: "El presente trabajo se hizo acreedor al premio único concedido por el Sr. Ministro de Defensa Nacional al ganador del concurso literario Vicuña Mackenna" (Prats 1957). 
Los hechos históricos narrados y las circunstancias en que las Memorias fueron redactadas permiten a Leonidas Morales integrarlas, legítimamente, en el tercero de los tres grupos en que clasifica el género autobiográfico en Chile. El primero corresponde a la formación del Estado de Chile; el segundo corresponde a la configuración de la identidad de la nación; y el tercero

es el de los memorialistas que podemos llamar contemporáneos. En el tiempo, son todos autores nacidos a fines del siglo XIX o comienzos del XX. Su memoria, en mayor o menor medida, es ya nuestra memoria, la de nuestro horizonte histórico inmediato [...] Los memorialistas contemporáneos rompen con esa homogeneidad [de clase], y en su lugar instalan una memoria de la diferencia, política, social y culturalmente (21).

Más adelante agrega:

La gran fractura social de 1973, la del golpe militar y la ominosa dictadura que inaugura, fue también, y paralelamente, una gran fractura de la memoria, individual y colectiva. 1973. No haré aquí su listado. Sería innecesario. Me limito a citar un par de títulos, imprescindibles por distintas razones [...] Las Memorias (1985) del general Carlos Prats (22).

Estas Memorias no se centran tanto en una introspección personal, pues se refieren a lo público, aunque sin pretensión de alcanzar una verdad histórica, sino más bien dar cuenta de un recuerdo, de legitimar la actuación del memorialista en circunstancias históricas y de defender una doctrina militar específica -y que tuvo gran impacto colectivo (Fierro 2005). Prats da cuatro razones para publicar su trabajo, de las cuales solo la última concierne directamente su persona:

Porque el destino me colocó, inexorablemente, en el trance histórico de participar en acontecimientos trascendentales de los últimos años de la vida nacional. Porque tuve la oportunidad de conocer secretos de Estado [...] que la Historia de Chile debe recoger. Porque supe la verdad de pugnas políticas que se han tergiversado maliciosamente ante la opinión pública. Porque fui testigo de actitudes nobles de personajes de alto nivel [...] así como de actitudes indignas de otros [...] Porque hubo hombres y mujeres que -anónima o públicamentezahirieron mi prestigio profesional y mi dignidad personal, sobre la base de la intriga, la calumnia, la injuria y la mentira (Memorias 46). 
En efecto, los tres primeros grupos de memorias tienen que ver con lo público, entendiendo por ello la definición de Leonidas Morales: las instituciones públicas son aquellas que son expresión de un poder y del Estado, pues, para él donde no hay instituciones públicas no habría tampoco condiciones para el cultivo del género memorias (Morales 2013, 23). Podemos, además, considerar que las Memorias tratan de lo que Stern denomina "memoria emblemática". Esta no sería una "cosa concreta", sino una especie de marco $\mathrm{y}$ forma de organizar las memorias concretas y sus sentidos y de organizar los debates entre la memoria emblemática y su contramemoria. "Da un sentido interpretativo y un criterio de selección a las memorias personales, vividas y medio-sueltas" (Stern 14).

Creemos que las Memorias de Prats cumplen con esa característica, es decir, realizan una selección de recuerdos para interpretarlos desde el punto de vista del interés público, cuyo contenido, para un militar, es específico, tal como veremos más adelante. Sin embargo, el concepto de "memoria emblemática", aunque justificado, es insuficiente para comprender algunos aspectos de las Memorias, porque superan el marco del recuerdo y de su interpretación: Carlos Prats, con ese escrito, actúa y profesa, conceptos que veremos en la Conclusión del presente artículo, aunque podemos adelantar que, aunque sean un hecho literario, se prestan también a un análisis desde el punto de vista de la teoría de la acción, porque una obra tan llena de contenido político es también, indudablemente, una forma de incidir en las instituciones de un país.

De momento, podemos afirmar que las Memorias de Prats contienen un Prólogo que se subdivide en tres partes: Acrimonia maliciosa, Proposiciones de un hombre a Dios y Carta a mis compatriotas. Posteriormente encontramos la narración de la articulación de dos instituciones centrales en la República de Chile: el ejército y el gobierno, contenida en los capítulos 1. Treinta y seis años de introducción 1931-1967; y 2. Veintiocho meses de desorientación militar. Mayo 1968-agosto 1970. El tercer capítulo da cuenta el desmoronamiento de esa relación: 3. Tres años de perturbación militar. Septiembre 1970-agosto 1973. Por último, en el cuarto se describe la destrucción de ella al superponerse el poder militar sobre el civil a partir del golpe de Estado de 1973: 4. Niebla sobre el campamento.

Es necesario recordar que el trabajo que aquí estudiamos fue escrito en el contexto de una fuerte tensión política, bajo amenaza de muerte, con premura y en medio de cierta precariedad, siendo concluidas diez días antes de su asesinato, que tuvo lugar el veinte de septiembre de 1974: 
Se me informó [después del golpe de Estado de 1973] que grupos fascistoides o esquizofrénicos me buscaban para matarme [...] Mi dedicación a una actividad comercial [tras un año de exilio en Argentina] y el hecho de no disponer de mi biblioteca privada, me han impedido finalizar la aspiración de escribir el libro que tenía proyectado desde largo tiempo atrás. Mi propósito primitivo era elaborar un Historial Mítico del Ejército, con la pretensión de ofrecer a mis conciudadanos un recuento epistemológico de la presencia del Ejército de Chile en la vida nacional, durante el devenir de nuestra evolución republicana, subdividido en los tramos históricos (48).

El concepto "epistemológico" lo trataremos en la sección subsiguiente, la número cuatro. El concepto de "historial mítico" no tiene explicación en las Memorias, aunque se puede deducir tanto del Diccionario de la Academia Española como del cuento "Tribunal de honor" (Prats, "Tribunal de honor" 1969). Por un lado, la tercera acepción que el Diccionario de la Real Academia Española da al término mítico es la siguiente: "3. m. Persona o cosa rodeada de extraordinaria admiración y estima" (Real Academia Española 2015). Naturalmente, lo que recibe esta admiración para Prats es el Ejército mismo. Por otro, el cuento "Tribunal de honor" explica dicha noción y le da el sentido cabal con que será usado en las Memorias. Ahora bien, "Tribunal de honor" no es un escrito de técnica militar, ni de historia militar, sino que pertenece a un género que suele ser clasificado "de ficción" - aunque no desconocemos la controversia del término en las disciplinas que estudian la narración literaria. Escrito en 1968, su argumento es el siguiente: el mayor Ramírez -personaje ficticio-, se encuentra escribiendo una obra sobre el ejército, la que titula “'Historial mítico del Ejército’ -en armonía con la técnica adoptada, de ir engarzando, comparativamente, la proyección de la vida del Ejército en la historia" (Prats, "Tribunal de honor" 1969). Se trata de una labor de defensa ante la sociedad de la institución a la que pertenece:

[El mayor Ramírez] Rememoró, fugazmente, la secuencia de su obra, a la que destinara cuatro a cinco meses de nocturnas jornadas; pero que, ahora, ya casi culminada, llenaba su ánimo de orgullo ante la perspectiva halagüeña del triunfo literario que, junto con realzar su prestigio profesional, contribuiría a enaltecer la presencia del Ejército ante la ciudadanía. Era urgente la necesidad de revitalizar en la opinión pública una clara conciencia de lo profundo y trascendente de la función militar, salvaguardia invisible de nuestra democracia, de la paz social y de la soberanía nacional. Había confirmado que aún en 
círculos cultos existían prejuicios negativos sobre la importancia de su función en la comunidad.

Para publicarla, el mayor Ramírez pide un préstamo a su superior. Ahora bien, su superior muere en un accidente de automóvil poco después de haber dejado sin protección documentos que contienen un secreto miltar, de los cuales se apodera un chantajista. El mayor Ramírez le paga diez mil escudos para recuperar los papeles robados, generándose así un triple conflicto: no puede devolver la suma a la viuda de su superior fallecido; tampoco tiene cómo financiar la impresión de la obra destinada a combatir los prejuicios negativos que la sociedad tiene del ejército; y, por último, no puede revelar la causa de no poder reintegrar el dinero, pues hacerlo implicaría revelar que lo utilizó para la recuperación de secretos militares, que nadie debe saber que existen. No pagar la deuda a la viuda de su superior fallecido no es en sí una falta militar, pero sí pone en entredicho el honor de los uniformados, de forma que se le somete a un tribunal de honor ${ }^{8}$. En el proceso, el mayor Ramírez prefiere la expulsión del Ejército a dar a conocer la existencia de un material que debe permanecer oculto, aceptando con ello el sacrificio personal que la vida militar le impone en aras del interés superior de la institución y del Estado, que requiere, para sus fines, que los militares cumplan autónomamente funciones que les han sido dados por el poder político legítimo.

Veamos ahora cómo se relaciona Prats con la redacción y la relevancia que tienen sus Memorias:

Mi objetivo literario era, obviamente, ambicioso y -como nadie tiene la vida comprada- en Buenos Aires recapacité, considerando la eventualidad de que me sorprendiera la muerte, dejando inconcluso un trabajo de tan largo aliento y en el convencimiento de que las nuevas circunstancias imponían la prioridad de registrar "mi verdad" frente a las catástasis que viví, excepcional para un militar chileno [...] Para el resto de mis compatriotas -especialmente para quienes fueron directos espectadores o protagonistas de los diversos hechos que específicamente comento- estas pruebas testimoniales serán

8 En 1968, el tribunal de honor del ejército veía los asuntos no sometidos al Reglamento de Disciplina y se regía por el artículo 203 del Código de Justicia Militar vigente entonces, cuyo precepto era: "Si algún oficial, de cualquier jerarquía que sea, cometiere un acto deshonroso para sí o para la unidad, cuerpo o repartición en que sirve, podrá ser sometido a un Tribunal de Honor, para que juzgue si puede continuar en él" (República de Chile 1944). 
útiles, como elementos de juicio, para corroborar o reajustar su propia apreciación de la gravísima coyuntura política que terminó por sumir en inexcrutable [sic] incertidumbre el porvenir de Chile (48-49).

Dicho propósito, en Prats, se ve alterado, y a la vez alentado, tanto por las circunstancias políticas como por la precariedad de materiales y la obligación de ganarse la vida en actividades comerciales durante el exilio. El propósito inicial de las Memorias, entonces, era realizar una historia del Ejército que relacionara y comparara la vida de este con la vida de Chile, una tarea no del todo distinta de la que se propone el personaje ficticio del mayor Ramírez. También Prats lucha contra los prejuicios, sobre todo contra los prejuicios de una parte de la sociedad hacia su propia persona en tanto esta encarna una doctrina militar, la de respetar la constitución. En nombre de esta doctrina, intenta contener tanto las tendencias extremas de derecha, que le ve servil a la Unidad Popular, como de izquierda, que ve en él una contribución a la renuncia por parte de Allende al programa revolucionario por el que fue elegido. La compleja situación política y personal, llena de incomprensiones, en que se encuentra Prats, se intensifica al integrar el gabinete cívico-militar. Stern sostiene que Allende, más que apoyarse en quienes realizan la revolución "desde abajo", decide apostar sus últimas posibilidades por un gabinete de seguridad nacional en agosto de 1973, con la participación de generales de las tres fuerzas armadas y carabineros, que cuenta con el asentimiento de Prats y del dirigente del Partido Comunista, Orlando Millas. El gabinete cívico-militar encuentra resistencia en los cordones industriales, donde el MIR tiene una influencia importante. Según Stern, Armando Cruces, dirigente de un cordón industrial, plantearía que era una traición y que producía desconcierto en el poder popular, pues Allende y el PC multiplican sus declaraciones honrando el constitucionalismo de los militares y denunciando el izquierdismo de los dirigentes del poder popular, sin alterar la pretensión por parte de algunos sectores de derecha de empujar a los militares al golpe (Stern 338).

En las Memorias, esa situación es descrita principalmente entre las páginas 330 a 477, narrando Prats, en esta última carilla, una manifestación de esposas de oficiales contra él mismo. Finalmente, el resumen de la situación, no personal, sino política, está planteado en estos términos:

Era imprescindible eliminar la polarización de clases [...] Era necesario neutralizar la creciente vigorización de los extremismos de ultraderecha y de ultraizquierda, que agravaban la motivación ideológica al crear las alternativas del golpismo fascista o de la dictadura del proletariado. 
Para el logro de estos objetivos de bien nacional, era responsabilidad del gobierno una salida política que diera garantías de estabilidad democrática y de continuidad del régimen constitucional (538).

Pocas páginas más adelante, con pesar, Prats agrega:

A petición del propio Presidente, me lancé en una verdadera cruzada de convencimiento a los dirigentes de los distintos partidos políticos de la Unidad Popular y de la propia Democracia Cristiana. No han faltado quienes la calificaron de 'ingenua'. Se me escuchaba con consideración, pero para que las profundas convicciones sectarias y el espíritu de intransigencia partidario, eran más fuertes que los temores a la eventualidad de una asonada militar (542).

Es entonces, en esta cuarta sección de las Memorias, donde se comprende el título de la primera parte del Prólogo, Acrimonia maliciosa, que cita un amplio número de juicios, muchos de ellos maliciosos, hechos ya sea por senadores principalmente de derecha y de la Democracia Cristiana -en especial Patricio Aylwin-, o por la prensa durante los meses inmediatamente posteriores al golpe de Estado de 1973. Es la prueba que confirma el planteamiento del mayor Ramírez: que aún en círculos cultos existían prejuicios negativos sobre la importancia de su función [del Ejército] en la comunidad y que motiva a este, como motiva a Prats, a aclarar esos prejuicios contrarios a las fuerzas armadas.

\section{LA FORMACIÓN DE LA DOCTRINA}

En un libro de 610 páginas, la maduración del contenido ético esencial de un militar en un ejército moderno, es decir, la subordinación al poder civil legítimamente constituido en el Estado, está descrita en tan solo siete carillas: de la 57 a la $63^{9}$, que corresponde a la edad de dieciséis años del futuro general. A este planteamiento, con pocas inflexiones, se le llamará más tarde "doctrina Schneider", sobre lo que volveremos. Las numerosas referencias a ese pensamiento, formado en Prats a los dieciséis años y que aparecen en las páginas que siguen del libro, no le agregan cambios fundamentales, sino que más bien describen su aplicación, incluso cuando Prats ha dejado el uniforme

$9 \quad$ Solo cinco líneas en esta última. 
y su acción continúa por escrito, durante el año en que redacta las Memorias. En efecto, son una forma literaria de continuar su acción a la vez militar y política, aun cuando se trate de una forma, algo desesperada y quizás también desesperanzada, de acción, propia de quien, como otros autores de memorias, están en desgracia y han dejado las armas: el trabajo de redacción se inicia poco después de comenzar su exilio, iniciado en septiembre de 1973. En 1974 Prats ve que uno de sus ideales, a la vez militares, políticos y personales -la doctrina de la subordinación de los militares a los civiles- ha sido derrotado, que los prejuicios se han impuesto sacando al ejército de su rumbo, que no son distintos de los que plantea el personaje del mayor Ramírez, es decir, "la salvaguardia invisible de nuestra democracia, de la paz social y de la soberanía (Prats, "Tribunal de honor" 1969)". En efecto, a continuación mostraremos que el conjunto de las Memorias se configura a partir de ese mandato, constituido a la edad de dieciséis años, cuya expresión resumida está encarnada en la figura ficticia del mayor Ramírez. En opinión del general Prats, todo militar debe cumplir con aquello, lo no que no le impide ver, con pesar, que a principios de la década de 1970 pocos oficiales estén dispuestos a satisfacer dicha exigencia $(234,379,478$, etc. $)$.

Las Memorias se inauguran con la narración de sus primeros años en la Escuela Militar, a la que entró en 1931, y los vagos conocimientos políticomilitares que tenía entonces.

Muy poco entendía entonces de lo que había sucedido desde el 'ruido de sables' de septiembre 1924, que había quebrantado la verticalidad del mando en el Ejército, al constituir una 'Junta Militar' [...] que provocó la petición de permiso constitucional del Presidente Alessandri para ausentarse del país e impuso la clausura del Congreso Nacional (58).

Prats continúa describiendo que el general Carlos Ibáñez, que llega al poder en 1927, se ve confrontado a fuertes tensiones políticas en 1931, motivadas por la crisis internacional de la época y porque "comenzaron a producirse graves alteraciones del orden público; la prédica de los políticos derechistas y la presión comunista, movilizaron las masas" (59). Es decir, Carlos Prats inicia su vida militar en un período convulsionado, tras un breve gobierno militar, y la elección democrática de otro militar al cargo de Presidente, pero este (Carlos Ibáñez), al no ver salida a las tensiones políticas

vaciló entre abandonar el gobierno o emplear el Ejército y la Armada en la represión [...] El Ejército estaba dispuesto a defenderlo, pero 
este 26 de julio [de 1931] opta por entregar el mando al Presidente del Senado [...] para evitar un derramamiento de sangre [...] Sólo en las últimas semanas, yo había tomado conciencia de que se vivía una tensa crisis política (59).

La primera lección que Prats sacará de ello se completa cuando el director de la Escuela Militar informa a los cadetes que abandona el Ejército, en virtud de la lealtad que le tiene al general Ibáñez: "es esta mi primera experiencia práctica [...] de lo que significaba aquella virtud militar de la lealtad" (59). Afirma después, Prats, que esas palabras se grabaron "con fuego en mi alma de adolescente, jurándome a mí mismo hacer un culto de la lealtad en mi carrera militar futura" (Memorias 59). La segunda lección, que deduce del hecho de que Ibáñez no decidiera hacer uso del Ejército con fines políticos, es el papel "que corresponde jugar al Ejército en una democracia representativa" (Memorias 60). Y, la tercera proviene de la descripción del motín de los suboficiales de la escuadra en Coquimbo, que el presidente Juan Esteban Montero derrota gracias a la intervención del Ejército y de la Fuerza Aérea, que dispara a los barcos rebeldes el seis de septiembre de 1931 (Memorias 61). Este hecho, de importancia política menor comparado con la renuncia de Ibáñez, es sin embargo el segundo ejemplo del concepto de lealtad militar, pues miembros de la Fuerza Aérea atacan a marinos amotinados, ataque con el que se garantiza la virtud militar de la lealtad. La lealtad militar, por tanto, se debe a la constitución de la República de Chile, incluso si ello obliga a disparar contra otros compañeros de armas; no es de forma alguna la lealtad al encubrimiento de la desobediencia a los poderes constituidos y menos al encubrimiento de crímenes. Tenemos, pues, ya dos líneas que serán continuas y que organizan la narración y la selección de las anécdotas: primero, la noción especificamente militar de lealtad, que no es lealtad entre los compañeros de armas, sino hacia el gobierno constitucional, como se comprobará mucho más adelante, en la página 431, que oportunamente analizaremos; y, segundo, el lugar del Ejército en la sociedad, que, como dirá posteriormente, no es tener roles, sino deberes (Memorias 580), lo que puede implicar exponer la vida y realizar sacrificios personales, como el personaje ficticio del mayor Ramírez.

Así también ocurrirá cuando Prats, ya Comandante en Jefe del Ejército de Chile, encabece la operación militar contra al regimiento rebelde Tacna que se subleva contra el presidente Allende el 29 de junio 1973, y ordene que se dispare contra los militares insumisos, que son derrotados ese mismo día (Memorias 417-426). En cuanto a su ética militar, en algunos aspectos, 
el joven cadete Prats es ya, en 1931, el mismo quien sería cuando asuma las responsabilidades de Comandante en Jefe en 1970 o lo asesinen en 1974. En consecuencia también de esa ética y doctrina militar se opondrá con las armas a otros militares: el 29 de junio de 1973 con motivo de la rebelión llamada "Tanquetazo", enfrentándose con su subametralladora a una columna de tanques (419-421) en una actitud a la vez valiente y de riesgo suicida.

El eje de esa ética es, también, la de un ejército moderno. ¿Qué entender por ello? Después de la Guerra del Pacífico y hasta el primer tercio del siglo $\mathrm{XX}$ la influencia prusiana se hace sentir en el ejército chileno, entre otros aspectos, por su profesionalización (Maldonado 1988, 4). El mismo Ejército rinde homenaje al general Körner al traer al país sus restos mortales y por medio de un artículo en la Revista Memorial del Ejército, entonces órgano del Estado Mayor. Körner había sido previamente director de la Escuela Militar, de forma que hacia agosto 1924 (fecha de la publicación), la mayoría de los generales y coroneles se había formado bajo esa inspiración y continuaron haciéndolo en la Academia Guerra. Asimismo, Körner fue jefe del ejército constitucionalista en la guerra civil de 1891 (116) (Estado Mayor del Ejército de Chile 1924). En el mismo número aparece el artículo Ideas sobre la instrucción de la infantería en Chile, del coronel prusiano Hans von Kiesling. La teoría de la profesionalización no se reduce al aspecto técnico, sino que tiene un componente político esencial, descrito por von de Clausewitz en su libro De la guerra (Clausewitz 2005 [1832]), a su vez uno de los aurtores más influyentes en teoría militar hasta la derrota de Alemania en 1918. Para Clausewitz, la guerra es un medio para un fin grave. La guerra se origina por un motivo político y por ello mismo esa es también la primera consideración cuando se trata de alcanzar sus logros. La política recorre todo el acto bélico y ejerce siempre una influencia en él, pues la guerra es un instrumento de la política. El mando militar puede exigir que las intenciones de la política no entren en contradicción con esos medios; estos pueden influir en la primera, pero la intención política es siempre el fin y no puede pensarse el medio sin el fin (Clausewitz 31). La subordinación de los militares a los poderes políticos legítimos, en consecuencia, se deduce de la naturaleza de la guerra y de la profesión militar, que es la de ser instrumento. De acuerdo con ello, el cientista político Genaro Arriagada sostiene que "[1]a profesión de oficial no puede ser ejercida de forma independiente ni en instituciones privadas, sino sólo en instituciones públicas, de ahí que el estudio de la profesión y del ejército se confundan" (Arriagada 1978, 27). Con ello, el mundo militar moderno se aleja de los grupos de mercenarios dispuestos a defender a pequeños o 
grandes señores en sus intereses propios, cuando estos no se distinguían de los del Estado moderno, que se caracteriza por la despersonalización de las instituciones políticas. Más adelante, Arriagada recuerda la distinción hecha por Clausewitz entre "guerra real" y "guerra absoluta", pues la guerra real no es absoluta, sino que se subordina a un objetivo político (Arriagada 1978, 35), por ser un instrumento de la política y no tiene por fin la destrucción total del enemigo, sino dejarlo indefenso (Clausewitz 17). La conclusión de Clausewitz -según Arriagada- será que los políticos no deberían influir en la carrera de los oficiales, porque estos son prescindentes de lo político (Arriagada 1978, 36), lo que supondría, también, que los militares no incidan en lo que es ajeno a su competencia. La interpretación que Arriagada hace de Clausewitz nos parece pertinente, al menos en cuanto a la modernización del Ejército de Chile, en cuyo proceso se inserta y Prats promueve durante su carrera. La doctrina de subordinación al poder civil es parte esencial de la profesionalización militar en un Estado de derecho, Estado que, mientras él llevó uniforme, vio avanzar.

El concepto de "historia mítica" del que hace uso Prats se esclarece aún más con la consideración de la reseña biográfica titulada, Benjamín Vicuña Mackenna y las glorias de Chile (Prats, Benjamín Vicuña Mackena y las glorias de Chile 1957); en ellas se entrelaza lo militar y lo civil, pero subordinando lo primero a lo segundo, tal como lo entiende el personaje ficticio del mayor Ramírez. La crónica sobre Vicuña Mackenna es una historia mítica, donde se reúnen la admiración, que la Real Academia Española incluye como parte del significado de la palabra "mítico", el entrelazamiento de lo civil y de lo militar, que es el significado que da el personaje Ramírez al término, y el recuento epistemológico sobre ello, es decir, la reflexión sobre esto último. Refiriéndose al impulso que, como político, Vicuña Mackenna dio a la modernización del Ejército, en muchos aspectos forzada por la Guerra del Pacífico, Prats sostiene:

Una de sus primeras campañas estuvo encaminada a lograr la introducción de algunas modificaciones fundamentales en la organización del Ejército. Vicuña Mackenna preveía las proyecciones de las campañas militares de largo aliento que sería necesario emprender para conseguir el triunfo y comprendía que la estructura orgánica de una Institución, preparada prácticamente para la guerra de Arauco [...] no estaba capacitada para expandirse en grandes unidades operativas [...]. Por tales razones Vicuña Mackenna fué [sic] un insistente propugnador de la organización racional del Estado Mayor del Ejército, organismo 
destinado a posibilitar la conducción de las operaciones terrestres en el Teatro de Guerra (38-39).

El concepto de "racionalidad" aplicado a la organización del Ejército lo podemos entender aquí justamente en el sentido moderno, una de cuyas expresiones filosóficas le da Hegel al afirmar que la racionalidad consiste en obrar respecto de fines (Hegel 26), que para un militar moderno es la guerra, cuyos fines, de acuerdo con la doctrina de Clausewitz, son políticos. La racionalidad de los fines, que constituye parte del núcleo político de la política moderna, se traslada en este caso desde una iniciativa política hacia lo militar, con lo cual se establece el vínculo entre ambas esferas sin traspasar la doctrina de la lealtad ni caer en el pretorianismo o imposición de anhelos militares a los civiles. La racionalidad de los fines debe ser provista por las instituciones políticas legítimas; Vicuña Mackenna, como civil, provee al Ejército de los medios para alcanzar los propósitos del Estado, de ahí su contribución a las glorias de Chile, las que son políticas, aunque se alcancen por intermedio del Ejército.

\section{LA DOCTRINA SCHNEIDER-PRATS}

El tratamiento que da el presidente Eduardo Frei Montalva a la sublevación del general Viaux el 21 de octubre de 1969 expresa un debilitamiento de la aplicación de la doctrina de la lealtad. El general Viaux se hizo fuerte en la sede del regimiento Tacna y obtuvo a su favor "la adhesión y la presencia de los alumnos de las academias de Guerra y Politécnica del Ejército en el Regimiento Tacna, quienes dejan en desmedrada posición a sus directores" (Memorias 126). Finalmente, el general Viaux abandona el cuartel tras la firma de un acta con el gobierno del presidente Frei, obteniendo la sustitución del Ministro de Defensa. Pocos días más tarde es sustituido el Comandante en Jefe, asumiendo el general René Schneider Chereau. Prats concluye, con pesar:

La verdad de esta ingrata dislocación de la disciplina institucional es que cuando se quiebra la verticalidad del mando, se empieza a rodar por las laderas [...] El 'acuartelamiento' del 'Tacna' tenía una finalidad política clara [...] Oscuros personajes civiles y uniformados se prepararon para mover las piezas del tablero de ajedrez [...] El jaque mate que 
condujera al derrocamiento de Frei se habría logrado por la dinámica de los acontecimientos si antes de 24 horas se hubieran materializado movidas maestras de otras piezas claves, pero la actitud del General Cheyre ${ }^{10}$, por una parte -aunque pueda calificarse de pasiva[...]- la inmovilidad de la I D[ivisión de] E[ejército] de Antofagasta por otra y, por último, la abierta disposición de la III D[ivisión de] E[ejército] para desplazarse en defensa del régimen constitucional, frustraron un conato golpista (126-127).

Vicuña Mackenna queda vinculado a las glorias de Chile por su labor de modernización del Ejército. Con el acuartelamiento de Viaux, el mundo militar se separa de la línea que se grabó "con fuego en mi alma de adolescente, jurándome a mí mismo hacer un culto de la lealtad en mi carrera militar futura" (Memorias 59). Traspasar esta línea es, también, alejarse los militares de la teoría moderna de la guerra propuesta por Clausewitz. La presión política de algunos civiles sobre el Ejército y sobre el Estado no cesa. Prats da cuenta de que los alegatos relativos a la sublevación de Viaux en la Corte Marcial son presenciados por unos trescientos oficiales y suboficiales, quienes asisten a título individual. Eso lleva al general René Schneider, entonces Comandante en Jefe, a prohibir la presencia de todo personal militar en actos públicos (Memorias 132). Más adelante agrega Prats que "son claros los indicios de que hay una conspiración en marcha, en la que habría oficiales del grupo de Viaux coludidos; pero no está clara la participación de políticos" (Memorias 136). Las páginas siguientes entregan algunos detalles de la investigación, que permite identificar a los sediciosos. Desde el punto de vista dramático, la conspiración contra Frei, aunque de escasa maduración, es un anticipo de nuevas conspiraciones y genera tensión y expectativas - pesimistas- en el narrador y en el lector. Es entonces cuando la doctrina profesional de subordinación al poder civil comienza a ser identificada con el pensamiento del general Schneider. Así lo expresa Prats:

En reunión con los oficiales del Estado Mayor de la Defensa Nacional, doy a conocer detalladamente la orientación impartida por Schneider [...] el poder militar está sujeto al control civil y su función es de absoluta prescindencia política, conforme a la actitud de no deliberancia [sic] que le impone la Constitución (Memorias 139).

10 Emilio Cheyre, padre de quien sería Comandante en Jefe durante el período 20032006, quien lleva el mismo nombre. 
En realidad, las Memorias revelan que esta doctrina, que se conocerá como la doctrina Schneider, era compartida entre los dos generales y amigos, y estaba presente en Prats desde los dieciséis años, por lo que debería recibir el título de doctrina Schneider-Prats, y que ella es una consecuencia indirecta de la profesionalización del ejército de inspiración prusiana y de teoría de la guerra expuesta por Clausewitz entre 1831 y 1853.

En efecto, en el marco de la historia mítica que, como hemos comentado, vincula la historia del Ejército con la historia nacional, Prats, siendo jefe del Estado Mayor de la Defensa Nacional, elabora, en acuerdo con los Comandantes en Jefe generales Schneider (Ejército) y Guerraty (Fuerza Aérea) y el almirante Porta (Armada), un "análisis del momento político nacional, desde el punto de vista militar" (Memorias 139). En él, Prats reitera la doctrina de subordinación profesional, afirmando que la "conciencia profesional" de las fuerzas armadas de Chile las constituye en un

factor de poder tradicionalmente marginado de la política contingente y seguro salvaguardia del imperio de la Constitución [...] Asegurada la cohesión de las FFAA, sus Comandantes en Jefe están en condiciones de garantizar el siguiente rol del poder militar [...] Apoyar firmemente al Poder Ejecutivo [...] Apoyar al candidato triunfante en un proceso electoral completo (Memorias 141-142).

Son innumerables, en las siguientes páginas, las referencias a actitudes de oficiales que buscan romper el papel subordinado de las fuerzas armadas, con o sin complicidad de algunos civiles. Cada uno de estos casos le sirve al narrador para recordar el deber de postura profesional del ejército. Como ya hemos dicho, el tercer capítulo se titula "Tres años de perturbación. Septiembre 1970-agosto 1973". En él se trata de una doble perturbación: una que afecta al profesionalismo militar y otra a las instituciones políticas del país. En estas páginas también la doctrina de la práctica militar como un ejercicio profesional es expuesta en plenitud con motivo de la figura del general Schneider y de la elección de Salvador Allende. Allende obtiene la primera mayoría en las elecciones presidenciales del viernes 7 de diciembre de 1970, pero no la mayoría absoluta, por lo que requiere un acuerdo del Congreso para asumir la jefatura del Estado. De acuerdo con las Memorias, Schneider, el mismo siete de septiembre, reitera, en un momento de gran tensión, la prescindencia del Ejército en materias políticas 
y dice que debemos ahora ser más consecuentes que nunca con lo que pregonamos durante la etapa electoral [...] el Congreso Pleno es soberano para elegir entre las dos primeras mayorías [Allende y Alessandri .... Se refiere a la gravedad de los días que se avecinan [...] Va a empezar un asedio constante y perseverante a todos nosotros, en todos los niveles, para tratar de convencernos de que sean las FFAA las que afronten el problema (167).

Las presiones se manifiestan hacia el mismo Prats, a fin de que "salve" la democracia (Memorias 170) y/o que desplace a Schneider. Incluso el aún presidente en ejercicio, Eduardo Frei, habría estado dispuesto a que Prats encabece un movimiento que envíe al extranjero a Allende (Memorias 172). Ahora bien, el 22 de octubre "un grupo de jóvenes de la alta sociedad, instigados por elementos de la ultraderecha y obedeciendo instrucciones de Viaux y sus colaboradores pretendieron secuestrar a Schneider para provocar una violenta reacción del Ejército, que impidiera la realización del Congreso Pleno" (Memorias 190), pero Schneider resiste y lo asesinan. El sábado 24 de octubre, el Congreso nombra a Allende Presidente de la República. En espera de que Allende asuma el cargo, Frei designa Comandante en Jefe a Prats, quien el seis de noviembre da a conocer un informe de aproximadamente setecientas palabras, titulado Definición Doctrinaria Institucional. En lo esencial, el documento reitera el papel de subordinación del Ejército:

1. La función del ejército es exclusivamente profesional [...] 5. Conforme al artículo 22 de la Constitución Política del Estado, el Ejército es parte constitutiva de la 'fuerza pública'. Por lo tanto, asegurará leal y firmemente -lo ha hecho siempre- la estabilidad del gobierno institucional (196).

El viernes 29 de junio de 1973 esa doctrina será nuevamente amenazada por una rebelión militar, conocida como "el tanquetazo", liderada desde el punto civil por Pablo Rodríguez Grez y otros miembros del movimiento de extrema derecha Patria y Libertad. En esa situación, el general Prats interviene directamente cerrando el paso con su propia persona a algunos tanques, a cuyos tripulantes ordena entregarse, uno a uno (Memorias 420). El 6 de julio 1973 sostiene una reunión con un grupo de generales (entre ellos Augusto Pinochet) ${ }^{11}$ y expresa una opinión que anticipa lo que sería el hecho de que las fuerzas armadas se alejen de la doctrina profesional: 
Insisto en que el 'cuartelazo' inicial es fácil, pero que las dificultades comienzan cuando se trata de gobernar contra la voluntad popular, imponiendo una tiranía feroz para doblegar la resistencia y exponiendo al país al desencadenamiento de una guerra civil, si se logra dividir a las FF. AA. Les añado que convertir al Ejército en una fuerza represiva interna, es destruirlo profesionalmente [...] Desahucio la tesis de 'no combatir entre compañeros de armas', porque ello significa impunidad para quienes infrinjan su deber de subordinación (Memorias 430).

Otros ejemplos constan en las Memorias de casos en que Prats expone o hace valer la doctrina llamada Schneider-Prats y también de cómo será sobrepasada. Valga lo expuesto de ella, sin embargo, para delimitar su evolución y contenido, que se resumen perfectamente en las 700 palabras de la ya citada Definición Doctrinaria Institucional.

\section{EL RECUENTO EPISTEMOLÓGICO}

Tenemos los hechos narrados. Recordemos ahora la pretensión con que Prats inicia sus Memorias: "ofrecer a mis conciudadanos un recuento epistemológico de la presencia del Ejército de Chile en la vida nacional, durante el devenir de nuestra evolución republicana, subdividido en los tramos históricos". No hemos encontrado la noción de "recuento epistemológico" en los textos de Prats leídos y pocas veces se encuentra en textos militares, pero hemos hallado tres casos. En el primero de ellos se encuentra la noción de "epistemología del proceso de planificación militar", que se refiere sobre todo a la planificación que interpreta una situación para detectar en ella la debilidad de este principio (Sanchez Flores 2016). El segundo uso lo encontramos en un documento del Comando de Institutos Militares de Bolivia, donde se afirma: "La epistemología es el conocimiento de la teoría de la Ciencia y Arte Militar. En cuanto a la teoría del conocimiento, casi toda la Ciencia Militar deriva de la experiencia; además, las hipótesis y el conocimiento del oponente o amenaza, son producto de la información procesada en inteligencia" (Comando de Institutos Militares de Bolivia 44). El tercer uso de la noción de "epistemología" en el contexto militar lo expone Sergio Prince y sería

la clasificación del conocimiento militar desde una perspectiva basada en los temas y problemas de estudio. De acuerdo con esta clasificación, la estructura de las ciencias militares se divide en 
un agregado de teorías: teoría del comando y control, teoría de las especialidades y servicios y así sucesivamente [...] las ciencias militares y sus especialidades adyacentes -las ciencias naturales, sociales y tecnológicas- pueden ser consideradas como un sistema de ciencias militares (Prince Cruzat 2008, 16-17).

Cabe entender, entonces, la pretensión de las Memorias como una exposición teórica -y no solo histórica- del lugar del Ejército en Chile y de cómo se forma en Prats la doctrina de la lealtad militar. Ahora bien: Mi objetivo literario era, obviamente, ambicioso y -como nadie tiene la vida comprada-en Buenos Aires recapacité. Es decir, el cambio de objetivo lo realiza Prats en Argentina, tomando en cuenta el golpe de Estado de 1973 y sobre todo el hecho de que nadie tiene la vida comprada. Es por el riesgo de muerte, realista y en cierta medida anunciado por varios indicios, el último por la negativa del gobierno de Pinochet de entregarle el pasaporte que por derecho le correspondía para viajar a Brasil ${ }^{12}$, que Prats combina el énfasis "epistemológico" con otro principalmente histórico, sin perjuicio de trasladar el primero de ambos aspectos al Epílogo, en la sección titulada "Niebla sobre el campamento" (Memorias 519-610). El golpe de Estado producido poco antes y el temor a morir le llevan a concentrar los primeros treinta y siete años de la primera sección (desde 1931 a 1968) en cuarenta y nueve páginas; la segunda, de mayo 1968 a septiembre 1970, en 54 páginas; y la tercera, de agosto 1970 a septiembre 1973, en 352. La cuarta sección (Epílogo) ocupa noventa y un páginas, y es el lugar donde Prats realiza una reflexión sobre el papel del Ejército durante la vida republicana de Chile. Conforme con ese recuento epistemológico, es decir, con una interpretación de los hechos narrados en los tres capítulos anteriores, afirma: "el breve lapso de la Historia de Chile comprendido entre los meses de septiembre de 1970 y de 1973, demuestra, irredargüiblemente, que nuestro país [...] ha vivido durante su evolución republicana la farsa política de la "Democracia condicionada" (Memorias 519).

Más adelante explica el carácter condicionado de ese sistema democrático "peculiar" y elástico, caracterizado por el equilibrio de poderes. Ahora bien,

los dirigentes políticos burgueses chilenos habían sostenido sistemáticamente $[\ldots]$ que eran 'absolutamente respetuosos de la

12 Eso daba tiempo a que los sicarios enviados por Pinochet prepararan el crimen en Buenos Aires. 
legalidad democrática'. Les faltaba, sí, añadir la frase... 'mientras no tengan acceso al poder los marxistas' (Memorias 521).

Las últimas páginas del Epílogo están dedicadas al Chile que debiera surgir, en una época indeterminada, después del golpe de Estado de 1973. En esas líneas, reitera el papel profesional que debe tener el ejército como garante de un Estado que deberá "expresar los intereses de la mayoría nacional, para que la política bregue eficientemente por un genuino 'interés nacional', capaz de manejar con realismo el factor común de los egoísmos individuales" (Memorias 548). Naturalmente, esa es una opinión, mucho más que un recuerdo, mucho más que una memoria, como son también opiniones las que da sobre la evolución del Estado chileno u otras afirmaciones sobre la dictadura que se instala en 1973:

La niebla se extendió sobre el campamento y la bestia, que dormita en lo íntimo del ser humano civilizado, despertó súbitamente con frenética avidez de víctimas [...] el 'asilo contra la opresión' se transformó, entonces, por la magia de Cirse, en el tinglado de la dictadura (Memorias 601).

Concluyen las memorias con un tono y un contenido similares a los del comienzo, cerrando así el ciclo abierto en las primeras páginas al comentar la renuncia del general Ibáñez. Su preocupación final es el "prestigio de los cuerpos armados" (Memorias 604), la "eficiencia profesional de los Institutos Armados, que no debe confundirse con el espíritu combativo" (Memorias 605), lo que está en consonancia con las aspiraciones del personaje ficticio del mayor Ramírez. Ahora bien, esto no significa, para Prats, una subordinación ciega a cualquier poder político, sino solo a un gobierno que carezca de legitimidad mayoritaria, pues aclara que las fuerzas armadas no son neutras, sino que son prescindentes de partidos políticos y no están al servicio de quien tome el poder ocasionalmente, sino constitucionalmente. La "filosofía de la 'democracia avanzada', que requiere de mecanismos de generación del poder que ofrezcan a la comunidad nacional la garantía cierta de que el gobierno, elegido libremente, sea genuinamente representativo de la Mayoría -con mayúscula-Nacional" (Memorias 606). El concepto de lealtad profesional de los militares no es, en consecuencia, ni abstracto ni indiferente políticamente; es la lealtad a ciertos principios políticos que Prats creyó estar encarnados en el sistema democrático chileno, reflejado en una constitución, sistema del cual se desengaña con la afirmación, ya citada, de que tenía vigencia "'mientras 
no tengan acceso al poder los marxistas"'. No es, por tanto, un vacío mental en materias políticas, pues supone tener claridad sobre a quién o a qué se debe la lealtad. La doctrina Schneider-Prats es heredera en ello de la teoría de la guerra subordinada a los fines políticos propuesta por Clausewitz. La eliminación de la polarización y la neutralización de los extremismos son parte de un bien nacional (538) que legítimamente puede procurar un militar al contribuir, con ello, a la mantención del régimen constitucional (538), con lo que se cumple el propósito de la profesionalización del ejército cuya descripción teórica correspondió a Clausewitz y que en Chile ponen en práctica Schneider y Prats.

La exposición teórica del papel del ejército en la vida nacional, es decir, el recuento epistemológico, interpretado desde la doctrina de la lealtad militar, constituye lo fundamental de la "verdad" (Memorias 48) que busca exponer en la principal de sus tres obras "literarias" ("Vicuña Mackena y las glorias de Chile"; "Tribunal de honor" y las Memorias). Entonces, la verdad contada no se refiere solo al hecho (las anécdotas militares y políticas narradas), sino a la valoración de los acontecimientos desde una teoría del papel profesional de las fuerzas armadas, que no equivale a una autonomía en relación con el Estado. El Ejército, en consecuencia, no es "“supercontrolador del interés nacional y de los altos destinos de la patria', sustituyendo la voluntad soberana del pueblo" (Memorias 607). Con ello, Prats, aun sin conocerla, toma distancia de lo que se institucionalizará en la Constitución de la República de Chile de 1990. Se trata, este último, de un caso que Genaro Arriagada define como pretorianismo o una forma particular de militarismo y de corrupción del sentido de lo militar (Arriagada 60).

El pretorianismo sería el uso abusivo de su poder armado en la designación del poder político y consiste "en que una clase militar ejerza un poder político independiente a través del uso de la amenaza de uso de la fuerza" (Arriagada 60). Naturalmente, el pretorianismo es ajeno a la teoría de la guerra de Clausewitz. El temor de Prats anticipa lo que serán los artículos 90, 93 y 95 de la Constitución Política de 1980 (República de Chile 1980). El primero estableció que "las Fuerzas Armadas [...] garantizan el orden institucional de la República" (República de Chile 1980, Art. 90). El segundo, que "los Comandantes en Jefe del Ejército, de la Armada y de la Fuerza Aérea, y el General Director de Carabineros serán designados por el Presidente de la República de entre los cinco oficiales generales de mayor antigüedad [y] no podrán ser nombrados para un nuevo período y gozarán de inamovilidad en su cargo" (República de Chile 1980, Art. 93). El tercero, que "[h]abrá un Consejo 
de Seguridad Nacional, presidido por el Presidente de la República e integrado por los presidentes del Senado y de la Corte Suprema, por los Comandantes en Jefe de las Fuerzas Armadas, por el General Director de Carabineros y por el Contralor General de la República [y] podrá ser convocado por el Presidente de la República o a solicitud de dos de sus miembros y requerirá como quórum para sesionar el de la mayoría absoluta de sus integrantes" (República de Chile 1980, Art. 95). En efecto, en primer lugar, la única institución estatal que la constitución de 1980 declara garante del sistema institucional civil son las fuerzas armadas; en segundo, la Constitución de 1980 restringió la libertad del Presidente de la República de elegir al comandante en jefe, y además hace a este inamovible por la misma autoridad que lo designa; y tercero, permitía que dos militares convoquen el Consejo de Seguridad Nacional incluso en contra de la voluntad del Presidente de la República, dejando al Jefe del Estado en una posición subordinada. Con ello, la Constitución de 1980 -antes de las modificaciones de 2005, producidas ya en democraciaconfirmaba el temor que anticipa Prats en el recuento epistemológico con que concluye las Memorias, pues se debilita la subordinación de las fuerzas armadas a los civiles y se establece un sistema pretoriano. Este recuento, por tanto, termina con una prognosis, alterando así la estructura convencional del género memorias, si bien el género no excluye, de ningún modo, la reflexión sobre un hipotético futuro, pues el género memorias no puede ser reducido a una crónica sobre el pasado. La singularidad de las Memorias de Prats, singularidad que probablemente se funde en el proyecto inicial de realizar un historial mítico y un recuento epistemológico, se incrementa al incluir una reflexión sobre el golpe de Estado de 1973 y el posible lugar del Ejército en el futuro del país. Ese futuro es el restablecimiento de la lealtad militar, que se traduce en un profesionalismo que debiera ser también el punto de partida del aprendizaje de todo oficial y que fue la primera virtud militar aprendida por Prats y quizás la principal de las virtudes castrenses que él practicó.

\section{CONCLUSIÓN: LEALTAD Y PROFESIÓN MILITARES}

Las Memorias manifiestan, más que una linealidad relativamente común en el género, cierta circularidad temporal que se organiza por medio de la profesión de lealtad, confirmando también con ello que la temporalidad narrativa se rige por reglas que no necesariamente son las de la cronología, de modo semejante a como propone Ricoeur en Temps et récit (Ricoeur 
1983). El segundo y tercer capítulos, que narran el período que va de 1968 a septiembre de 1973, describen hechos esencialmente políticos, que tienden a alejar, tanto desde dentro como de fuera de ellas, a las fuerzas armadas chilenas de la lealtad con la que Prats abre su aprendizaje militar. Esa lealtad es la que se desarrolla durante la vida uniformada de Prats y que desea ver de regreso tras una hipotética restauración democrática, que se narra en el Epílogo. Las Memorias son una narración sobre la lealtad en el campo de la profesión militar. Esta profesión, restaurada, sería una forma especial de ser militar, la moderna, y al mismo tiempo heredera de la doctrina de Clausewitz, pero sin desconfiar de los civiles. Se aplica a la idea de profesión militar, no solo un aprendizaje técnico, sino las dos primeras acepciones del verbo profesar: "1. tr. Tener o mostrar un sentimiento o una actitud hacia alguien o algo. Le profesan cariño, admiración. 2. tr. Defender o seguir una idea o una doctrina" (Real Academia Española, lema "lealtad"). Las Memorias muestran que el sentido del profesionalismo militar, para Prats, es más de lo que cabe en la definición que Arriagada realiza de un militar profesional: estar guiado por una calificación técnica, responsabilidad, código de ética y solidaridad entre sus miembros (Arriagada 4). Las Memorias muestran que un militar no practica un oficio, sino que lo profesa, conforme con el hecho de que defiende o sigue una idea o doctrina. ¿Cuál? La lealtad al poder civil en una “'democracia avanzada', que requiere de mecanismos de generación del poder que ofrezcan a la comunidad nacional la garantía cierta de que el gobierno, elegido libremente, sea genuinamente representativo de la Mayoría -con mayúscula- Nacional" (Memorias 606). Es, finalmente, la figura literaria del mayor Ramírez la que ofrece, no de un modo teórico, sino por la encarnación en un personaje ficticio, la clave interpretativa de las Memorias $\mathrm{y}$, a la vez, permite articular y organizar narrativamente la memoria personal con la memoria del jefe militar y vehicular por medio de esa articulación el contenido político del texto. Como ya hemos dicho, en el caso de Prats, la memoria escrita no se limita a un recuerdo, sino que es una forma de acción y de defensa del papel del Ejército profesional en medio de la acrimonia de la incomprensión política y personal, similares a los prejuicios negativos que quiere superar el mayor Ramírez. Es memoria y es historia, superando la oposición que establece Pierre Nora (Nora 1984). El sentido político de las Memorias no es separable de las referencias a la obra literaria de Prats y a su articulación en relación con el tiempo histórico que le tocó vivir. 


\section{BIBLIOGRAFÍA}

Amorós, Mario. “Archivo Chile”. (1999). Archivo Chile. Centro de Estudios Miguel Henríquez. 10 de noviembre de 2017 <www.archivochile.com/Ideas_Autores/amorosm/1/1amorosm0018. pdf $>$

Arriagada, Genaro. El pensamiento político de los militares; estudio sobre Chile, Argentina, Brasil y Uruguay. Santiago de Chile: Aconcagua/CISEC, 1978.

Clausewitz, Carl von. De la guerra. Trans. Carlos Fortea. Madrid: La esfera de los libros, 2005 [1832].

Comando de Institutos Militares de Bolivia. Comando de Institutos Militares. 20 de 09 de 2017 <www.libroesoterico.com/biblioteca/.../filosofia\%20Militar.pdf>

de Gaulle, Charles. Mémoires. Ed. Marius-François Guyard. Vol. 1. París: Gallmard, 2000 [1954]. 1 vol.

Estado Mayor del Ejército de Chile. "La llegada al país de los restos del General de División don Emilio Körner”. Memorial del Ejército de Chile Año XIX (1924): 115-119.

Fierro, Juan Manuel. "El discurso de la memoria en Chile (1970-2005)". Valdivia, noviembre de 2005. 227, más anexos.

González. "Homenaje en memoria del general Carlos Prats. 30 de septiembre de 2014". República de Chile. Diario de las sesiones del Senado. 15 de septiembre de $2017<\mathrm{http} / /$ www.senado.cl/appsenado/index.php? $\mathrm{mo}=$ sesionessala\&ac $=$ getDocumento\&teseid $=535$ $59 \&$ nrobol $=\&$ tema $=$ Homenaje\&legiid $=\&$ parl_ini $=34 \&$ tagid $=10>$

Hegel, George William Friedrich. "Phänomenologie des Geistes". Hegel, George William Friedrich. Werke. Vol. 3. Frankfort: Suhrkamp. 21 vols. 1986. 598.

Jouhaud, Christian, Dinah Ribard y Nicolas Schapira. "La littérature pour politique: étudier les Mémoires". Les temps modernes 661.5 (2010): 85-97.

Maldonado, Carlos. "Entre la reacción civilista y constitucionalismo formal: las fuerzas armadas chilenas en el período 1931-1938”. Contribuciones 55 (1988): 96.

Morales, Leonidas. "Memoria y géneros autobiográficos". Anales de Literatura Chilena 19 (2013): 13-24.

Nora, Pierre. "Entre memoria e historia: la problemática de los lugares". Les lieux de la mémoire. Trans. Fernando Jumar. Seminario de Historia Argentina, Univ. Nacional del Comahue, Neuquén. París: Gallimard, 1984. XVII - XLIL.

Prats Cuthbert, Sofía; Cecilia Prats Cuthbert y María Angélica Prats Cuthbert. "Presentación". Prats, Carlos. Memorias. Testimonio de un soldado. Santiago: Pehuén, 1984. 610.

Prats, Carlos. "Benjamín Vicuña Mackena y las glorias de Chile". Memorial del Ejército 279 (1957): 13-48.

Prats, Carlos. "Tribunal de honor". 9 de Febrero de 1969. Carlos Prats. 21 de septiembre de $2017<\mathrm{http}: / /$ www.carlosprats.cl/?page_id=114>

Prats, Carlos. Testimonio de un soldado. Ed. Juan Andrés Piña. Santiago: Pehuén, 1985.

Prince Cruzat, Sergio. "Los fundamentos de las ciencias militares". Revista Política y Estrategia 111 (2008): 14-28. 
Real Academia Española. "Lema “profesar"”. Diccionario de la lengua española. Madrid: Real Academia Española, 2015.

República de Chile. "Constitución Política de 1980". 8 de agosto de 1980. www.camara.cl. Cámara de Diputados. 27 de septiembre de $2017<$ https://www.camara.cl/camara/media/ docs/constitucion_politica.pdf>

República de Chile. 19 de diciembre de 1944. Código de Justicia Militar DFL 2226. Ed. Ministerio de Justicia. Bibliteca del Congreso Nacional. 20 de septiembre de $2017<$ https:// www.leychile.cl/Navegar?idNorma=18914>

Ricoeur, Paul. Temps et récit 1. Vol. 1. Paris: Seuil (Coll. "L'ordre philosophique"), 1983. 3 vols.

Sánchez Flores, Julio. "Epistemología del proceso de planificación militar”. 17 de abril de 2016. Jaque Mate. 20 de 09 de $2017<$ http://jaquematereydos.wixsite.com/jaquemate/singlepost/2016/04/27/Epistemolog\%C3\%ADa-del-Proceso-de-Planificaci\%C3\%B3n-Militar-1>

Solís, Alejandro. "Jefe del Ejército Carlos Prats". 01 de 10 de 2014. Youtube. Teletrece. 02 de octubre de $2017<$ https://www.youtube.com/watch?v=r6pxUPwa-rs>

Soto, Hernán y Juan Arriagada. Prats, un proyecto inconcluso. Ed. Juan Arriagada. Santiago de Chile: Radio Universidad de Chile, 2014.

Stern, Steve. "De la memoria suelta a la memoria emblemática: hacia el recordar y el olvidar como proceso histórico (Chile, 1973-1998)". Garcés, Mario et al. Memoria para un nuevo siglo: Chile, miradas a la historia de los últimos cincuenta años. 1 vol. Santiago: Lom Ediciones, 2000. 11-33.

Varas, Augusto. “El régimen militar en Chile (1973-1985)". Araucaria de Chile 33 (1986): 27-42. 